\title{
Labour movement in India - A historical approach on socio-cultural-economy
}

\author{
Apurba Chakraborty \\ Inspector of College, University of Gour Banga, Malda, West Bengal, India \\ *Corresponding Author: Apurba Chakraborty \\ Email: drapurbaic@gmail.com
}

\begin{abstract}
The working class history in India had been drawing a prominent graphic throughout the changing framework of colonial cultures. British rule in India changed the self sufficient village economy which was an outstanding feature in term of economics. To analyze the working class mobility one Question remain to be answered, why in spite of changing periphery the poor conditions of labour was unchanged? At the time of formative stages of the industry most of these were built by British businessmen, so as a part of colonialism organized working class was another changing need. Our mainly objective in writing the article is to pay attention to the growing role of working class in Indian society.
\end{abstract}

Keywords: Industrialization, Poverty, Marginal farmer, Non agricultural labour, Trade union, Proletarianization.

\section{Introduction}

Discussion on Labour movement in India was a wide range description in Indian working class History. Non agricultural labour and a class relational approach was present in the colonial legacy to concrete social setting. Landless labour and marginal farmers were discussed on the light of rural poverty. Indian culture was saturated with religious values and ideas as it was structured by the rural economic condition of the country. The need base agricultural economy had been changing before in the year of 1840 due to the British industrial revolution needed raw material for their industry. Historians were tried to discuss Indian working class movement phase wise, such as age of Early Industrialization and emerging of working class (1840-1900), working class movement (1850-1947) was a vast period in history so this period divided in to five phase, first phase (1850-1900), second phase (1900-1914), third phase (1915-1922), fourth phase (1923-1939) and fifth phase (1940-1947). The segment wise labour movement was organized to various part of India and emergence of early labour consciousness. Dipesh Chakraborty in his book 'Rethinking Working Class History 1890-1940' had tried to analyze deep roots of the substance of class consciousness.

\section{The fall down of the urban agriculture sector working class on early colonialism effects}

From the very beginning Indian working class history had been bearing a tradition which was not to compare with another country. In the post Palasy fighting (in the year of 1757) radically changes had occurred in Indian sociocultural- economy. East India company tried to capture the India so that administration pattern of the state was becoming frequently changing. According to historical scholarly micro label study on actual working class history of the age of beginning of the colonialism was obtained absent. Labour history came to lighting through the organisation in initially stage of 20th century's India. After formation of the All India Trade Union Congress (AITUC, 1920) the industrial labour were organist in India throughout a new shape. Working class in India was an increasing number on population of India. Working class History and its growth in abroad was a systematic way, industrial revolution had took place in England according to result of industrialization. In Indian context working class had been popular thorough a continuous movement. India had grown an economy which had mainly agricultural based before British industrial revolution. After 1800 India was a major raw material supplier country for the purpose of the British industrial revolution. Indian productions of cotton, coal, jute were very cheap and best raw materials. Having incriminating demands of those raw materials in England, peasantry of India were pushed to a new economic challenges. A Continuous increasing exploitation of the farmers of agriculture fields change crops production tradition and they were bound to cultivate cotton as if cheap raw material could be exported to England. In the midnineteenth century, in true sense industrialization in India had introduced by the establishment of tea industry in Assam (1839), Bengal Coal Company (1843), first cotton mill in Bombay and jute mill in India (1854). It is notable point that jute and cotton industry played important role in the economic structure which was radically changing their pattern in context of the colonial effects. Tea plantation workers and railways workers were identified as platforms of huge employment opportunity. From the writing of Walter Hamilton in his 'Description of Hindustan' in 1820 mentioned regarding existences of towns and cities of India at beginning of the nineteenth century.

\section{Working class in formative stage on the eve of the twentieth century}

The first concept of industrial labour had came by the establishment of the tea plantations industry which was mentioned as semi industrial revolution in Indian. Industry was compared with agriculture and considering no doubts, much lesser role in providing a means of living. The significance of industry in the economy of the country and in social life was better than agriculture in colonial India (Urban Development in Indian since Pre Historic Times, by B Bhattacharyya). 
The age of the twentieth century is marked as age of beginning of the trade union. Near about 1900-1914, the total number of worker in industry were highly increased. If we consider the data of the industry it was recorded that 264 textile mills, 64 jute mills were established within the year 1914. The shape of industrialization of India grown in this year.

Factors contributing to organisation since rapid developments British industry

England needed huge raw material for industrial revolution. In this purpose colonial country of the England had become good number of raw material supplier and they were influenced by the ruler to cultivate the raw material which was needs for industry instead of Traditional crops.

Wage workers and non-wage earners were played important role in rural economy. One of the first concerns of course is the relative size of the proletarian labour force in the population. In this regard in "The Indian Labour Year Book 1997" provided some interesting information. According to the 1991 census, 'workers' constituted $37.5 \%$ of the whole population of the country. The term 'workers' here taken to mean all those gainfully employed and not as wage-workers. Out of these, 'cultivators' accounted for $38.41 \%$. Similarly fishers, animal herders, hunters etc. accounted for another $1.90 \%$. This means, $40 \%$ of the working population of the country were insignificant producers and small property owners. To deep root discussion its observe the Peasants, Agricultural Workers and Industrial Workers had close relationship with each other in every aspects. The diagram mentioned below is made clear indication of the gradual proletarianization of the rural population.

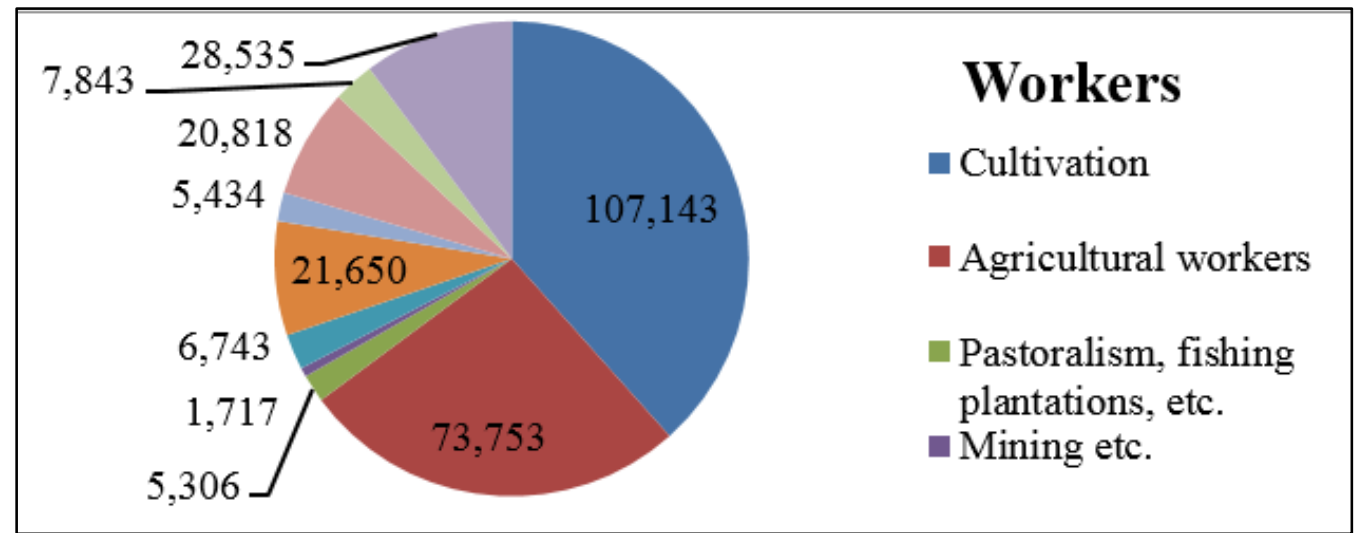

Source: Census 1991

Workers of the cultivation had the major portion of the total number of the working class as well as factor of the wages were high proportionately. This is also reflected in case of percentage of each working class against the total work force.

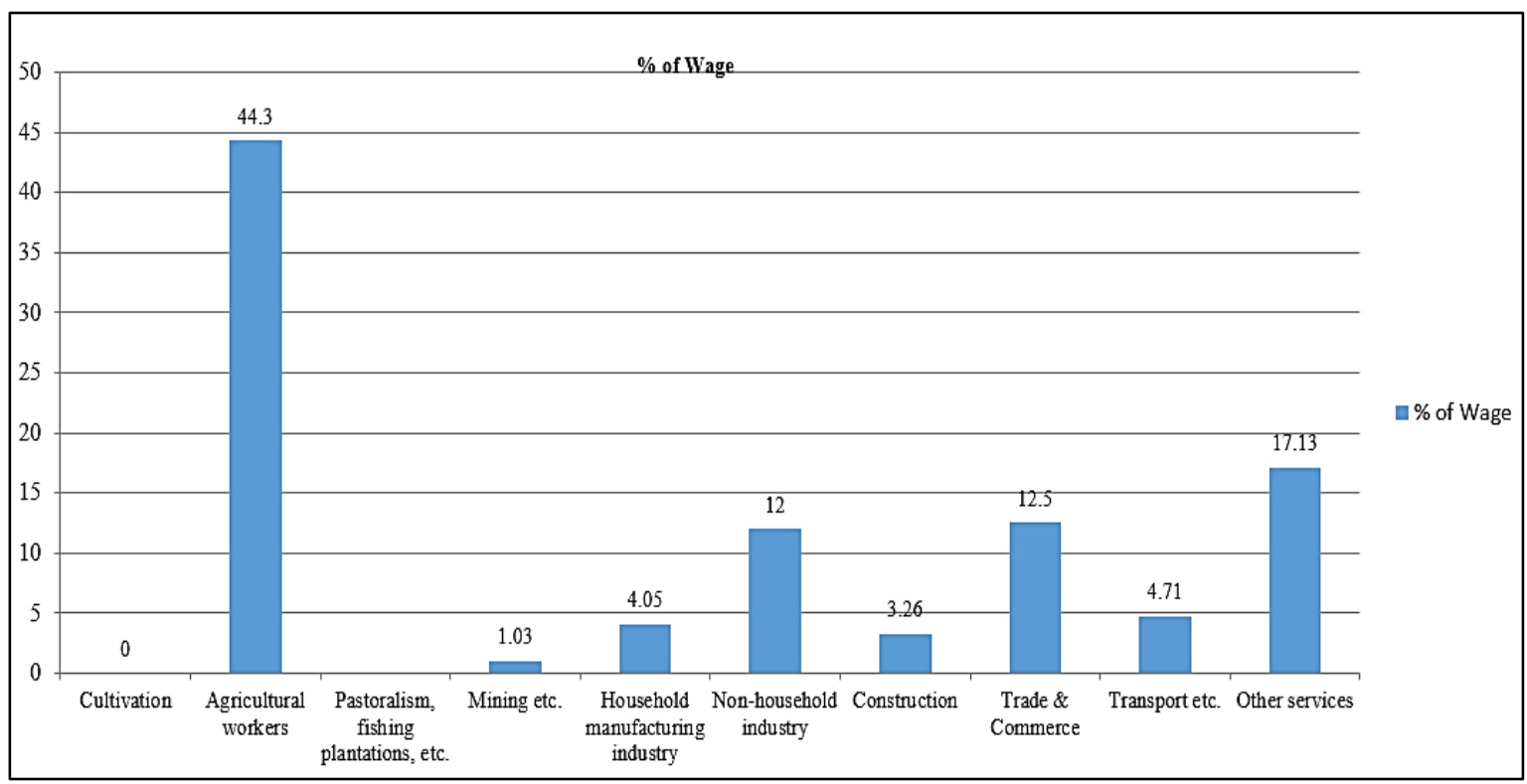

Source: Census 1991 


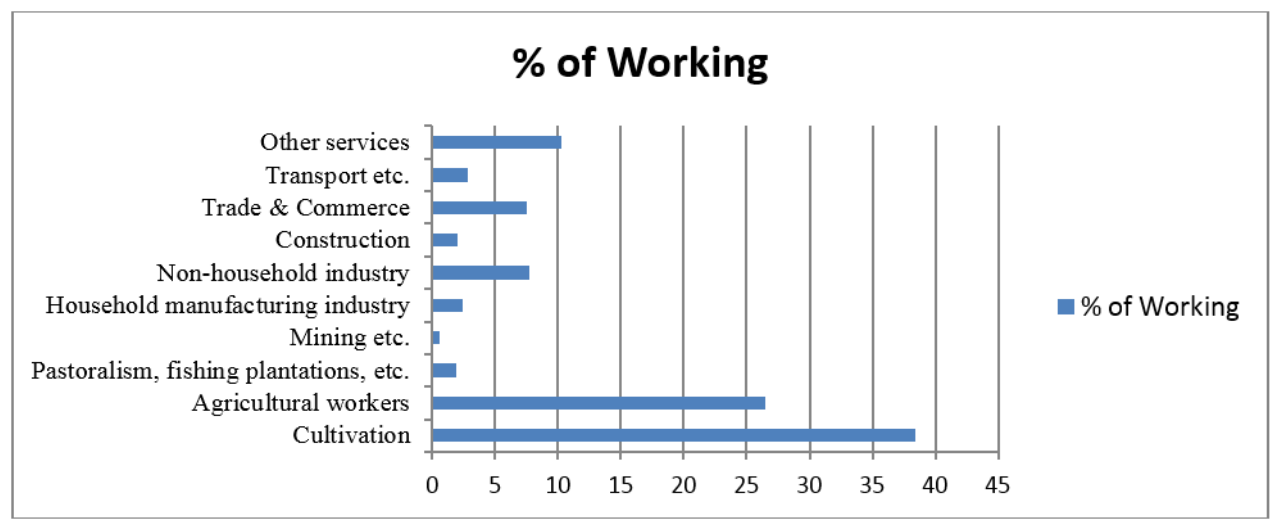

Source: Census 1991

\section{The role of small scale working class unit as initial stage of organisation}

Working class and the path of organisation was not an easy process in colonial autocracy. V. B. Karnik in his book 'Strike in India 'clearly mentioned Continuous labour disputes in cotton industry, jute industry and railways workers in various part of the India. Labour of the cotton industry of Gujarat. Factory industry and factory labour brought in its wake many an industrial problem, the problems of terms and conditions of employment, of recruitment and retention, of absenteeism and hours of work, of industrial relations and of industrial disputes and their settlement. This study is concerned only with the problem of strikes, the method used by workers for ventilating grievances and securing their redress. The study will be to trace the origin of this phenomenon in the early years of the growth of industries. Workers were organised on a need based demand such as working hours reduce, wage increase and demand for betterment of living conditions etc. Most of the cases strikes took place locally, in this regard it was notable thing that out sides leadership involvement had took place for organization in the industry. Sujata Patel in her book "Making of Industrial Relations. Ahmedabad Textile Industry 1918-1939" mentioned that how the workers of textile industry were engaging through the middle man involvement. On question of outside leaders involvement in organised labour disputes and continuous strike in the textile industry had come in the writing of working class history as a critical research.

\section{Conclusion}

Working class history in India had left a picture of continuous movement and industrial disputes against their employer. It had come to notice that during the second half of the nineteenth century agriculture land of the country was under pressure. Due to unequal competition with British machines, the cotton and small industry of India had been going to collapse. From the end of British government any initiative had not taken for improvement of agriculture without encouraging for cultivation of Commercial crop. If we considered the views about state then the state was a gadget of a class that got its initial impetus from serving under the colonial power.

\section{Source of funding}

None.

\section{Conflict of interest}

None.

\section{References}

1. Bhattacharya, B. (n.d.). Urban Development in India.

2. Chakrabarty D. (n.d.). Rethinking Working-Class History: Bengal 1890-1940. Retrieved from https://www.jstor.org/stable/j.ctv3hh57s

3. Patel, S. (1987). The making of industrial relations: the Ahmedabad textile industry, 1918-1939. New York, NY: Oxford University Press, USA.

4. Raj, M. K., \& Aruna, D. (2008). Women Farmers of India. NBT India.

5. Subramanian, C. N. (n.d.). Size and Structure of the Labour Force. Retrieved from https://www.revolutionarydemocracy.org/rdv6n2/labour.html

How to cite this article: Chakraborty A. Labour movement in India - A historical approach on sociocultural-economy. J Manag Res Anal 2019;6(3):129-31. 